\title{
URBANIZAÇÃO, HABITAÇÃO E SEGREGAÇÃO SOCIOESPACIAL
}

\author{
URBANIZATION, HOUSING AND SOCIAL SEGREGATION
}

\section{Andrea Lise Campos Suriano ${ }^{1}$ Paulo Romano Reschilian²}

RESUMO: Esse artigo tem como objetivo apresentar um estudo sobre o processo de urbanização de São José dos Campos, derivado dos desdobramentos históricos das transformações socioespaciais ocorridas com o processo de consolidação da urbanização capitalista (desde o advento da Revolução Industrial). Pode-se constatar a forma pela qual o processo de urbanização acelerada, aliado à intensificação da industrialização, contribuiu para aumentar o deficit habitacional no município e produzir a segregação socioespacial. Vale destacar que se pode considerar o exemplo de São José dos Campos inserido no padrão típico de consagração de um "urbanismo à brasileira".

Palavras-chave: urbanização; habitação de interesse social; segregação socioespacial; cidades médias; São José dos Campos.

ABSTRACT: This article aims to contribute to a study on the process of urbanization in São Jose dos Campos derived from the historical developments of socio-spatial transformations occurring in the process of consolidation of the capitalist urbanization (since the Industrial Revolution). The process of fast urbanization, coupled with intensified industrialization, has contributed to an increase housing shortage in the city and has produced severe socio-spatial segregation. São José dos Campos can be considered as an example of the typical pattern of a consecration of "Brazilian urban planning".

Keywords: urbanization; social spatial segregation; social housing; São José dos Campos.

\footnotetext{
${ }_{1}^{1}$ Mestranda em Planejamento Urbano e Regional - Universidade do Vale do Paraíba - Univap. E-mail: lise.andrea@yahoo.se. 2 Doutor em Arquitetura e Urbanismo - Universidade de São Paulo - USP e Professor Titular da Univap. E-mail: paromano@uol.com.br.
} 


\section{INTRODUÇÃO}

A terra e a sua propriedade privada são questões fundamentais para solucionar a questão habitacional (VILLAÇA, 1986, p 3). A questão da terra está no centro dos conflitos sociais que alimenta a desigualdade social (MARICATO, 2008).

Segundo Maricato, o aumento de favelas, de cortiços e de loteamentos irregulares, a partir da segunda metade do século $X X$, resulta de um processo de urbanização segregador com características da sociedade patrimonialista do Brasil prérepublicano (MARICATO, 1996).

É preciso entender porque o papel da aquisição da terra, do processo de urbanização e da industrialização é tão importante, para que se possa entender a forma de organização do território. $E$, derivado desse processo em escala global, perceber como esses elementos foram fundamentais para a configuração, em países periféricos, como o Brasil, do padrão de urbanização que consagrou a lógica da segregação socioespacial que ocorreu nas cidades brasileiras.

O avassalador processo de urbanização, aliado à transformação do meio natural para o meio técnico cientifico informacional, modernizou o modo de vida, "sem deixar, entretanto, de reproduzir seu lado arcaico. Isto é, a modernização é apenas para alguns; a cidadania, idem" (MARICATO, 2003, p. 79).

Nesse sentido, a precarização das relações sociais de produção inseridas no processo de acumulação de capital tornouse evidenciada no espaço urbano por meio da organização espacial das moradias das diversas classes sociais.

Desde que foram "expulsos" do campo, durante a Revolução Industrial, na Europa dos séculos XVIII e XIX, os camponeses conseguiram acesso à habitação, apenas em moradias precárias, nas cidades pouco preparadas para recebêlos. A terra, transformada em mercadoria, teve seu valor agregado à infraestrutura que a cerca. E esse valor impôs à população de baixa renda um elevado preço ao acesso à terra urbanizada (VILLAÇA, 1998).

No caso brasileiro, tanto quanto em outras cidades médias dos paises da periferia do capitalismo, os loteamentos irregulares e as favelas surgem como as únicas alternativas de moradias para as populações de baixa renda e "(...) continuarão a se reproduzir enquanto o mercado privado e os governos não apresentarem alternativas habitacionais" (MARICATO, 2003, p. 82).

A dificuldade da aquisição da terra urbanizada, articulada a outros fatores, como a auto-segregação da população de alta renda, e a locação espacial diferenciada dos investimentos em infraestrutura, caracteriza o espaço urbano e a segregação socioespacial vivenciada pelas cidades brasileiras a partir da segunda metade do século XX (PEGORETTI; SANCHES, 2004).

Em São José dos Campos, a intensa industrialização brasileira, atrelada à urbanização acelerada, produziu um intenso aumento populacional a partir da década de 1940. Nesse contexto, o número de favelas e loteamentos irregulares passou a ser crescente, visto que a população de baixa renda não teve acesso à aquisição de terra urbanizada e a segregação socioespacial se acentuou.

Dessa forma, enquanto a população 
de favelados aumentava gradualmente, o Poder Público viu-se obrigado a ter que investir em habitações populares, para que a produção de favelas fosse erradicada (PMSJC, 1977).

Nessa direção, a politica habitacional adotada pelo município de São José dos Campos, foi a de remoção de favelas e construção de conjuntos habitacionais na periferia, em parceria com a agência estadual CDHU (Companhia de Desenvolvimento Habitacional e Urbano do Estado de São Paulo), bem como de fontes externas de financiamento ${ }^{1}$, o que colaborou para aumentar ainda mais a segregação socioespacial.

A partir dessa perspectiva, o presente artigo tem como objetivo analisar como o processo de urbanização de São José dos Campos, aliado à intensificação da industrialização, contribuiu para aumentar o déficit habitacional no município e produzir a segregação socioespacial.

\section{O PROCESSO DE URBANIZAÇÃO EM SÃO JOSÉ DOS CAMPOS}

São José dos Campos, situado na região leste do Estado de São Paulo, no Vale do Paraíba Paulista, tem sua origem associada à formação da Aldeia do Rio Comprido no século XVI. Em 27 de Julho de 1767, a então São José do Paraíba, passou de Aldeia à Vila; e, em 1864, foi elevada à categoria de cidade.

Dista cerca de $90 \mathrm{~km}$ da cidade de São Paulo. Possui área total de 1.099,6 km²; sendo a área urbana de $361,95 \mathrm{~km}^{2}$ e a população de 629.921 habitantes (IBGE, Censo 2010).

O sistema produtivo do Brasil Colonial, baseado na economia exportadora de produtos primários, determinou a urbanização das cidades brasileiras, como São José dos Campos, que surgiram como sedes burocráticas e como sedes do capital comercial. A maior parte da população habitava as cidades litorâneas, que se constituíram como a sede do capital, e tinham papel comercial, administrativo e religioso. Eram poucas, porém, grandes cidades, que formaram uma rede urbana pobre, porém polarizada (OLIVEIRA, 1982).

\footnotetext{
${ }^{1}$ Em 2001, com financiamento do BID (Banco Interamericano de Desenvolvimento), a Prefeitura construiu 453 unidades habitacionais na periferia da região leste da cidade, e transferiu para o bairro recém criado, Jd. São José, os moradores das favelas Nova Detroit, Caparó e Tatetuba.
} 


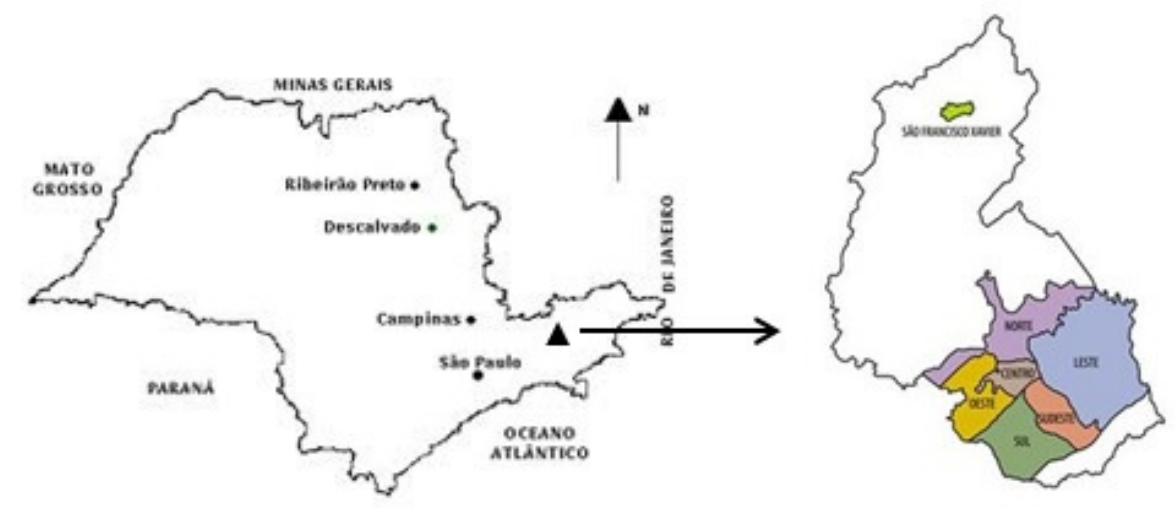

Fig. 1 - Mapa do Município de São José dos Campos - destaque para a área urbana. Fonte: PMSJC (2011).

Para assegurar o desenvolvimento das plantations ${ }^{2}$, foi promulgada a Lei das Terras (Lei $n^{\circ}$ 601/1850). Essa lei criou obstáculos à aquisição da terra e impelia os camponeses e os imigrantes a continuarem a trabalhar nas plantations, constituindo o latifúndio como a unidade básica da Colônia.

A circulação das mercadorias obrigou - Estado a investir em infraestruturas de circulação, para garantir que esses itens produzidos nos campos chegassem às cidades portuárias (OLIVEIRA, 1982). São José dos Campos alcançou seu crescimento econômico, sustentado, principalmente, pela produção de algodão e pela cultura cafeeira, que trouxe ao município a estrada de ferro em 1877.

Em 1924, foi inaugurado o Sanatório Vicentina Aranha, o maior sanatório do país, e a cidade experimentou um grande crescimento urbano. A partir de 1935, no governo Vargas, a cidade foi instituída Estância Climática e pôde contar com investimentos para infraestruturas. $\mathrm{O}$ período Sanatorial durou até o final da

2 Plantation era um sistema agrícola baseado na monocultura, na exportação de gêneros primários e na exploração da mão de obra, geralmente, escrava. década de 1950, quando passou a haver um maior incentivo à vinda de indústrias para o Vale do Paraíba.

A aceleração da industrialização brasileira, depois da crise mundial, em 1929, e do início da economia baseada na exportação cafeeira, veio atrelada ao fato de "uma industrialização inteiramente urbana e requerendo taxas de urbanização muito acima das que seriam as necessidades de preenchimento dos postos de trabalho nas novas fabricas" (OLIVEIRA, 1982, p. 44).

O Brasil, até então, era formado por cidades em uma frágil rede urbana, por arquipélagos regionais polarizados por suas metrópoles e capitais regionais. Com a modernização industrial e da economia, foi se formando uma rede interligada, primeiramente entre as regiões Sul e Sudeste, que, depois, incorporaram o Nordeste e, por fim, o Centro-Oeste e o Norte.

A partir do governo de Juscelino Kubitschek e seu Plano de Metas, o Brasil teve seu território modernizado, com a construção de rodovias, grandes hidrelétricas e indústrias de base que 
exigiram mais mão-de-obra nas cidades.

Em um prazo relativamente curto, a maior parte da população brasileira perdeu seus meios de produção/sobrevivência, foi expulsa do campo e começou a trabalhar nas indústrias, em troca de salários irrisórios, e a habitar moradias insalubres. Essa urbanização e industrialização acelerada, calcada em baixos salários, vai gerar a chamada "modernização excludente" (MARICATO, 2000, p. 123), traduzida por um crescimento econômico significativo, porém condicionado à manutenção da pobreza (FERREIRA, 2011).

Os investimentos públicos em infraestrutura foram concentrados nas áreas ocupadas pela população de alta renda, e a consequência disso, no âmbito urbano, é a segregação socioespacial e um modelo de "urbanização desigual" ou urbanização "à brasileira", como define Ferreira (2011). Esse processo de urbanização se refletiu na forma de precariedades das habitações da população de baixa renda.

Em São José dos Campos, a inauguração da Rodovia Presidente Dutra, em 1951, serviu como elemento polarizador, o que resultou em uma intensa valorização imobiliária de terrenos próximos à rodovia, mais bem servidos de infraestrutura e, por isso, disputados pelas indústrias e pelos loteamentos residenciais para a população de alta renda. A população de baixa renda, que migrava para trabalhar nas indústrias, ocupou loteamentos populares e clandestinos, principalmente na área rural.

Houve um grande fluxo migratório, na década de 1950, devido à expansão industrial, quando foram inaugurados o CTA (Centro Técnico Espacial), o ITA (Instituto Tecnológico de Aeronáutica), a GM (General Motors em 1959), Ericsson (1955), entre outras. Nas décadas seguintes, foram implantadas, na cidade, a EMBRAER, a Avibras, a Engesa e o Instituto de Pesquisa Espaciais (INPE) e, assim, a cidade foi se tornando um grande polo tecnológico.

Essa transformação de cidade Sanatorial em Polo Tecnológico Industrial Aeroespacial está associada à terceira fase da descentralização industrial no Estado de São Paulo $^{3}$ e à politica de apropriação tecnológica do II Plano Nacional de Desenvolvimento (1975-1979) que implicou na instalação das grandes indústrias nas cidades próximas a São Paulo, como São José dos Campos.

Com a consolidação da economia baseada em indústrias, São José dos Campos teve um grande aumento populacional que acelerou o processo de urbanização. A população quase dobrou entre os anos de 1960 e 1970. Na década de 1970 , cresceu mais de $190 \%$. Não só a migração rural-urbana, mas também a migração proveniente de outros municípios, o que fez com que a cidade duplicasse sua população em menos de 30 anos.

Os grandes espaços ocupados pelas indústrias, pela linha de transmissão de energia, pela ferrovia, pela rodovia Dutra, pelo Rio Paraíba e pelo Banhado (várzea do Rio Paraíba) tornaram-se obstáculos à expansão do tecido urbano contínuo. A habitação passou a ocupar os espaços que não eram considerados adequados às grandes indústrias, ou por não serem extensos ou por não serem planos (SILVA, 2008).

\footnotetext{
3 Costa (1982 apud SOUZA; COSTA, 2010), divide a descentralização industrial ocorrida no Estado de São Paulo em: fase 1 , quando apresenta a suburbanização da indústria; fase 2, na década de 1950, quando as indústrias seguem em direção às Rodovias Anchieta, Anhanguera e Presidente Dutra; e fase 3, a partir da década de 1960, quando a descentralização se estende por uma área de $100 \mathrm{~km}$ distante de São Paulo.
} 
Na década de 1970, a escala do crescimento foi maior que a implantação de loteamentos, construções de edifícios e conjuntos habitacionais. A demanda por habitação fez elevar o valor da terra urbanizada e ocasionou a utilização de glebas rurais para expansão, assim como o aumento de núcleos de favelas (ROSA FILHO, 2002).

Desde que foi atribuído à terra um valor de mercadoria e com os investimentos em infraestrutura sendo feitos para garantir o escoamento da produção, privilegiando os setores de atuação da população de alta renda, a localização de um lote passou a ter seu valor agregado à infraestrutura que o cerca. O valor da localização, segundo Villaça (1998) contribui para que a população de baixa renda ocupe as periferias das cidades, menos dotadas de infraestrutura; e isso faz com que o acesso à terra urbanizada seja o centro do conflito social; e a maior causa do crescimento desenfreado de favelas e loteamentos ilegais (MARICATO, 2008).

A especulação imobiliária, o preço elevado do solo urbano e a complexa legislação de regulação de acesso à terra, tornaram o mercado formal de habitação restritivo à população de baixa renda, sobrando apenas a alternativa de ocupar áreas desprezadas pelo mercado formal, como as encostas dos morros e as áreas de proteção ambiental.

A produção do espaço urbano, fruto da articulação entre proprietários de terra e imóveis, construtoras, poder público e concessionarias de serviços públicos, resulta em uma segregação socioespacial e como apresenta Torres e Gonçalves

$$
\begin{array}{llr}
(\ldots) \text { a lógica de valorização } & \text { sistemática dos ativos }
\end{array}
$$

imobiliários nas áreas mais ricas da cidade tem impactos significativos na estruturação e dinâmica urbana. A principal consequência resulta que (...) um menor numero de moradores tem acesso ao chamado centro expandido (...) um numero maior de pessoas tenha que buscar a periferia e favelas como alternativa de moradia (2007, p. 21).

No Mapa da Pobreza de São José dos Campos, elaborado com dados do Censo de 2000 observa-se que de acordo com o indicador da condição de domicilio, 32,36\% da população urbana vivia em setores com índice muito critico e critico; e no aspecto referente à condição social do responsável pelo domicilio, $15,85 \%$ da população urbana tinha os responsáveis com renda mensal de até um salário mínimo (BORGES, 2004).

A cidade continuou a receber imigrantes em busca de trabalho, e entre 1991 e 2010 a população do município saltou de 439.231 mil habitantes para 629.106 mil habitantes, um aumento de $43 \%$ em apenas duas décadas. O "deficit" habitacional estimado em 2003 era de 2.560 residências (PMSJC-NEPO, 2003); e o número de inscritos na fila para a casa própria era de 14mil em 1996. Além disso, a Prefeitura Municipal de São José dos Campos monitorava 95 loteamentos irregulares em 2011 (PMSJC, 1995).

Em síntese, pode-se observar em São José dos Campos os mesmos processos de urbanização pelos quais passou o país, o que produziu uma cidade espraiada, apoiada no sistema de transporte rodoviário, apresentando desigualdades sociais e um urbanismo segregador. 


\section{A POLÍTICA HABITACIONAL} MUNICIPAL

A habitação entrou na agenda do poder público municipal como um programa para erradicar as favelas. Em 1973, havia apenas 4 núcleos de favelas em São José dos Campos.

Com intenção de iniciar a erradicação das favelas, foi entregue, em 1976, o Conjunto Habitacional São Judas Tadeu, na região sudeste, na época uma distante zona periférica, para abrigar a população das favelas, especialmente da favela Linha Velha (na parte central da cidade), que foi removida para a construção da Avenida Fundo do Vale e do novo Paço Municipal (ROSA FILHO, 2002).

Em 1977, já existiam 12 núcleos de favelas, e a prefeitura elaborou o Primeiro Plano de Desfavelamento, cuja intenção era manter os moradores no tecido urbano, reurbanizando as favelas. Entretanto, antes mesmo desse Plano começar a atuar, foi sancionada a Lei no 2007/78, que instituiu a criação da Empresa Municipal de Habitação (EMHA), com a principal diretriz de planejar e executar programas de erradicação de favelas, cortiços e outras habitações inadequadas.

Apesar da proposta inicial do plano ter sido a de manter os moradores das favelas no tecido urbano, o que ocorreu foi a transferência da população das favelas localizadas nas áreas centrais para loteamentos periféricos, como o Conjunto Elmano Ferreira Veloso, na região Sul, em 1980.

Segundo Forlin e Costa (2010), esses programas não atenderam à população que recebia até 3 salários mínimos, pois 0 financiamento de lotes urbanizados e casas populares eram voltados para a população cuja renda era de até 10 salários mínimos. Dessa maneira, o número de favelas continuou aumentando e, em 1982, totalizava 17 (ROSA FILHO, 2002).

O final dos anos 1980 e início dos anos 1990 foi o período mais expressivo do Déficit habitacional, devido, tanto à crise econômica que se abateu sobre o país, quanto pela Lei Federal 6766/79, que criminalizou o loteamento clandestino (ROSA FILHO, 2002, pp. 50-55).

Em 1992, a nova administração, diferentemente do que havia sido feito nas administrações anteriores, adotou a política habitacional de investir na urbanização de favelas e na regularização de loteamentos irregulares, e criou o Conselho Municipal de Habitação e o Fundo Municipal de Habitação, com o intuito de construir casas populares, garantindo, assim, o acesso à infraestrutura, ao transporte e ao emprego.

Essas ações não tiveram continuidade nos governos seguintes, uma vez que a mudança da administração preconizou a diretriz de remoção de favelas. Em 1996, a cidade tinha 19 favelas, localizadas, a maioria, na Zona Norte. Com o processo de Desfavelização, esse número caiu para apenas 7, em 2004.

Nota-se que os recursos (na Tabela 1, observam-se as parcerias) para esses empreendimentos vieram do próprio município. A $\mathrm{CDH}$ (Companhia de Desenvolvimento Habitacional do Estado de São Paulo) enfrentava uma crise, uma vez que 0 sistema $\mathrm{SFH} / \mathrm{BNH}$ (de onde provinham seus recursos) havia entrado em colapso e o Banco Central, diante da inadimplência e da crise econômica no país, proibiu que fossem feitos empréstimos. 

Tabela 1 - Empreendimentos da Política Habitacional Municipal de São José dos
Campos entre 1976 e 2011

\begin{tabular}{|c|c|c|c|c|}
\hline Parcerias & Empreendimento PMSJC & Região & $\begin{array}{c}\text { Unidades } \\
\text { Habitacionais }\end{array}$ & Ano Entrega \\
\hline Prefeitura & Torrão de Ouro & Sul & 100 & 1976 \\
\hline Prefeitura & Conj Hab São Judas Tadeu & Sudeste & 150 & 1976 \\
\hline Prefeitura & $\begin{array}{c}\text { Conj Elmano Ferreira Veloso - } \\
\text { embriões de } 10 \mathrm{~m}^{2}\end{array}$ & Sul & 850 & 1980 \\
\hline Pref/CEF & D Pedro I & Sul & 2000 & 1991 \\
\hline Pref./CDHU & D Pedro II & Sul & 1041 & 09/11/1996 \\
\hline Pref./CDHU & D Pedro II & Sul & 685 & $25 / 09 / 1997$ \\
\hline Prefeitura/CDHU & $\begin{array}{l}\text { Vila Iracema (Jd. São Judas / } \\
\text { PM) }\end{array}$ & Sudeste & 428 & $1997 / 1998$ \\
\hline Prefeitura & Henrique Dias & Centro & 64 & 2000 \\
\hline Prefeitura/CDHU & Campo dos Alemães (mutirão) & Sul & 82 & $04 / 05 / 2000$ \\
\hline Prefeitura/CDHU & Campo dos Alemães (mutirão) & Sul & 82 & $24 / 02 / 2001$ \\
\hline Prefeitura/CDHU & Campo dos Alemães (mutirão) & Sul & 82 & $15 / 12 / 2001$ \\
\hline Prefeitura/CDHU & Campo dos Alemães (mutirão) & Sul & 54 & $15 / 06 / 2002$ \\
\hline Prefeitura/CDHU & Jardim São José ॥I & Leste & 453 & 2003 \\
\hline Prefeitura/CDHU & Campo dos Alemães (mutirão) & Sul & 158 & $28 / 01 / 2005$ \\
\hline Prefeitura/CDHU & Papa João Paulo II & Sul & 342 & 2006 \\
\hline Prefeitura/CEF/CDHU & Residencial Ribeira & Leste & 177 & 2006 \\
\hline Prefeitura/CDHU & Campo dos Alemães (P.Q) & Sul & 121 & 2006 \\
\hline Prefeitura & Centro & Centro & 8 & 2007 \\
\hline Prefeitura/CEF/CDHU & São José II & Leste & 20 & 2007 \\
\hline Prefeitura/CEF/CDHU & Santa Inês III & Leste & 42 & 2007 \\
\hline Prefeitura/CDHU & Vila Rossi "Vila César" & Norte & 8 & 2008 \\
\hline Prefeitura/CEF & Vila Leila & Norte & 63 & 2008 \\
\hline Prefeitura/CDHU & Luchetti & Centro & 55 & 2009 \\
\hline Prefeitura/CDHU & Dom Pedro I -C. Alemães & Sul & 14 & 2009 \\
\hline Prefeitura/ $\mathrm{CDHU}$ & Frei Galvão & Leste & 416 & 2010 \\
\hline Prefeitura/CDHU & Santa Inês I (vertical 1+4) & Leste & 128 & 2010 \\
\hline Prefeitura/CDHU & São Geraldo & Norte & 110 & 2010 \\
\hline Prefeitura / CDHU & Putim & Sudeste & 132 & 2010 \\
\hline Prefeitura / CDHU & Boa Vista & Norte & 256 & $2010 / 2011 / 2012$ \\
\hline Prefeitura / CDHU & $\begin{array}{l}\text { Parque Interlagos/ Torrão de } \\
\text { Ouro }\end{array}$ & Sul & 524 & $2011 / 2012$ \\
\hline
\end{tabular}

Fonte: PMSJC (2012); CDHU (2012).

Após a Constituição de 1988, que garantiu autonomia aos Estados e, a partir de 1990, do acréscimo de receita do ICMS (Lei 6556/89) à CDHU (Companhia de Desenvolvimento Habitacional e Urbano do
Estado de São Paulo), a Companhia estadual passou a lançar programas habitacionais de produção em massa.

O resultado dessa nova política 
habitacional estadual pode ser percebido em São José dos Campos, nos conjuntos habitacionais entregues entre 1991 e 1998, caracterizados pela grande quantidade de unidades habitacionais, na mesma gleba, pela modalidade do programa adotado (SH3) e por continuar localizando os empreendimentos na periferia da cidade, longe da infraestrutura consolidada.

O programa adotado para a construção da maioria dessas moradias, Empreitada Global SH3, é um dos dois subprogramas previstos no Pró-Lar Núcleo Habitacional por Empreitada, lançado pela Secretaria de Habitação do Estado de São Paulo. Esse programa prevê a construção de unidades habitacionais, em conjunto habitacional urbano, em parceria com as Prefeituras Municipais, por empresa contratada após licitação, em regime de empreitada.

À Prefeitura cabe a doação dos terrenos e a implantação da infraestrutura básica (abastecimento de água, esgoto, iluminação pública, energia elétrica), a gestão de equipamentos sociais (escolas, creches, coleta de lixo, postos de saúde etc.), e o cadastramento, habilitação e entrega das chaves à população.

Aqui, cabe a explicação de que as terras utilizadas pela Prefeitura, para a implantação dos loteamentos, na região sul do município, tem sido a área conhecida como Campo dos Alemães, declarada de interesse social e desapropriada em 1980, por meio do Decreto no $2899 / 79$, que possui $2.620 .763,67 \mathrm{~m}^{2}$ (ROSA FILHO, 2002, p. 98).

À CDHU é atribuída a vistoria e aprovação do terreno doado, elaboração de projetos arquitetônicos e de urbanismo, licitação e contratação das empresas construtoras para a execução e fiscalização das obras.

A Secretaria de Habitação define as diretrizes e critérios para concessão de financiamentos e subsídios aos beneficiários dos programas.

Ao analisar-se o resultado da politica municipal de habitação, observa-se que a parceria com a CDHU é responsável por $63 \%$ das unidades habitacionais produzidas no município; portanto, a diretriz da Companhia estadual, em todas suas fases, é importante para entender a forma como se deu a ocupação do território pela população atendida.

Nesse sentido, nota-se que, quando a CDHU adota, no final da década de 1990, a política de diversificar os programas para atender a demandas diversificadas, pode-se observar em São José dos Campos, a implantação de conjuntos habitacionais por meio de Mutirões, e, em outras regiões da cidade, em terrenos periféricos menores e com menos unidades habitacionais, também porque a gleba Campo dos Alemães já havia sido quase que totalmente ocupada.

A falta de terras baratas perto do centro e das áreas mais providas de infraestrutura faz com que a escolha dos lotes gere tanto mais precariedade quanto os loteamentos irregulares, uma vez que as casas são entregues à população sem a devida infraestrutura urbana necessária sem asfaltamento nas ruas, com poucas ou inexistentes linhas de transporte publico, sem equipamentos sociais próximos. $E$ isso implica dizer que o poder público tornou-se executor de uma situação que deveria combater.

Diante do exposto, pode-se considerar a expansão das periferias e sua consequente segregação socioespacial, 
como o produto do processo de urbanização à brasileira, sofrido pelas grandes e médias cidades, como em São José dos Campos SP.
Na Fig. 2 observa-se que os conjuntos habitacionais construídos estão localizados nas periferias da cidade.

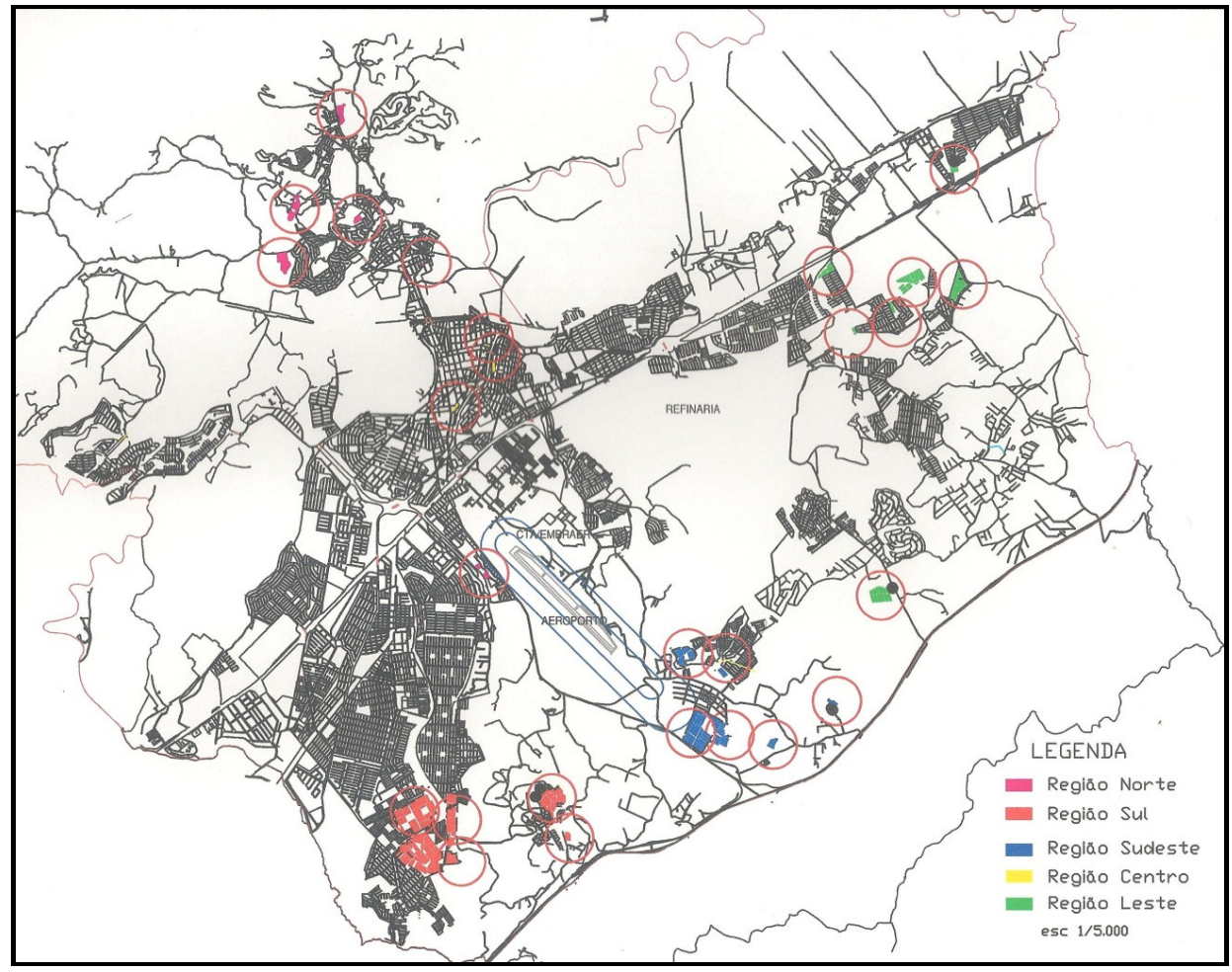

Fig. 2 - Localização dos Empreendimentos construídos entre 1976 e 2011. Fonte: PMSJC (2012); CDHU (2012).

Sabe-se que o espaço urbano é resultado de uma complexa relação entre os processos políticos, econômicos e culturais e, ao analisar-se a localização desses conjuntos habitacionais, pode-se perceber a organização desses espaços urbanos em zonas segregacionistas, resultantes desses interesses ideológicos, econômicos e políticos.

Segundo Villaça (1998), os atributos mais representativos da segregação residencial na América Latina são os de ordem socioeconômicos.

Pode-se somar a isso, um dos padrões de segregação definido por Marcuse (2004), o qual afirma que a segregação das classes sociais reflete e reproduz as relações de poder e pode ser representada pela distribuição dos serviços públicos, pelo Estado. Os acessos diferenciados à infraestrutura urbana a equipamentos educacionais, de saúde e de lazer tornam-se a expressão materializada da atuação da sociedade na produção do espaço urbano, como sugere Castells (1983). Isso se reflete, no território, pela maneira como os setores socioeconômicos se apropriam do espaço urbano: as elites controlam a produção e as relações sociais e se valem de instrumentos do Estado e do mercado imobiliário para garantir a manutenção do seu modo de vida. 
Em São José dos Campos, percebese a segregação socioespacial no padrão centro-periferia - na forma de loteamentos irregulares, nas periferias da cidade, e, também, na formação de "enclaves fortificados", os condomínios fechados horizontais ou verticais - onde existe uma aproximação física entre as classes, porém com uma grande separação social (CALDEIRA, 2000).

Na Fig. 3 observa-se a concentração de moradias da população de alta renda nos bairros centrais (3, 4 e 20) e da região oeste
(17 e 18), enquanto a população de baixa renda habita as regiões mais periféricas, caracterizando a separação física entre essas populações. Os bairros 13 e 14 experimentaram, entre os anos 2000 e 2010 , a construção de modernos empreendimentos verticais, para a classe alta, que demandaram do poder publico municipal a incrementação do sistema viário, uma vez que essa parcela da população desloca-se, apenas, com o uso de automóveis individuais e exige a modernização e facilitação dos acessos aos seus setores de atuação.
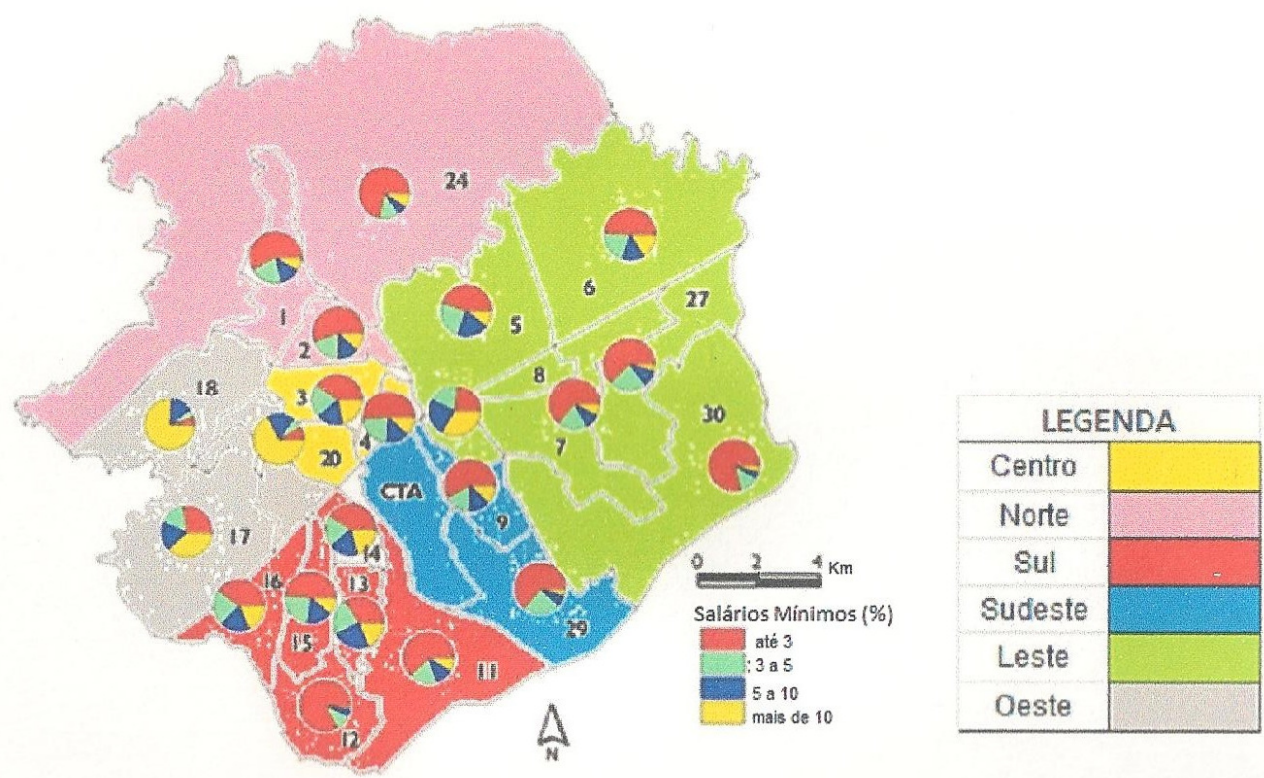

Fig. 3 - Distribuição de renda total das famílias, em salários mínimos, setores socieconômicos em 2003.

\section{Fonte: Pesquisa de Instrumentação do Planejamento Urbano e Avaliação do Deficit Habitacional em São José dos Campos.}

Fonte: PMSJC (2003).

\section{CONCLUSÃO}

Procuramos mostrar, neste artigo, como a segregação socioespacial apresentada em São José dos Campos é produto de um processo de "urbanização à brasileira", que perpetuou a manutenção dos conflitos socioeconômicos, principalmente no acesso â aquisição da terra, e intensificou a periferização da cidade ao permitir a implantação de conjuntos habitacionais de interesse social em locais 
com pouco ou nenhuma infraestrutura consolidada.

Procuramos demonstrar que a segregação socioespacial, em São José dos Campos, ocorre pela falta de acesso à aquisição de terras baratas (pelo baixo poder de consumo da população de baixa renda) e, também, pela forma como os programas habitacionais adotados foram implantados no território.

A ação da Prefeitura de São José dos Campos, por meio dos diversos Planos e Programas de Habitação, desde 1977, em parceria com o Estado ou com o Governo Federal, atuou na perspectiva de retirar os moradores de favelas das zonais centrais e realocá-los em bolsões de moradia de interesse. Fica evidente que esse processo perpetua a segregação socioespacial que advém das alterações ocorridas nas relações capital/trabalho, desde a Revolução Industrial e age no exercício da cidadania, quando diferencia 0 acesso às políticas públicas, de acordo com a renda monetária e a localização espacial da moradia.

O debate sobre segregação espacial tem se demonstrado como parte de um processo que envolve diversos sujeitos nas diversas esferas da sociedade civil e do Estado. A presente análise da atuação do poder público, por intermédio dos programas habitacionais, confirma a efetiva importância de se aplicar os instrumentos urbanos que garantam o acesso à aquisição de terras baratas e com infraestrutura.

Portanto, torna-se inevitável refletir sobre o papel do Estado e das políticas públicas, sobretudo na esfera dos governos locais e da governança metropolitana (principalmente após a recém-criação da Região Metropolitana do Vale do Paraíba, da qual São José dos Campos pertence), no que diz respeito à habitação e ao direito à cidade da população de baixa renda.

\section{REFERÊNCIAS}

BORGES, L. S. Mapa da pobreza urbana de São José dos Campos /SP 2000. In: XIV Encontro Nacional de Estudos Populacionais (ABEP), 20-24 set. 2004, Caxambu-MG.

CALDEIRA, T. P. Cidade de Muros: crime, segregação e cidadania em São Paulo. São Paulo: 34/Edusp. 2000.

CASTELLS, M. A Questão Urbana. Rio de Janeiro: Paz e Terra, 1983.

CDHU. Companhia de Desenvolvimento Habitacional e Urbano do Estado de São Paulo. Produção habitacional: São José dos Campos, 2012. Disponível em: $<$ http://www.cdhu.sp.gov.br/producaonew/oferta-cdhu.asp?Pag=ofertacdhu\&situacao $=3 \&$ dest $\mathrm{Hab}=1$ \& municipio $=37$ $4 \&$ Nome $=S A O$ JOSE DOS CAMPOS $>$. Acesso em: jan. 2012.

FERREIRA, J. S. W. Cidade da intolerância ou urbanismo à brasileira. Revista de Estudos Avançados, São Paulo, v. 25, n. 71, p. 73-88, jan./abr. 2011.

FORLIN, L. G. COSTA, S. M. F. da. Urbanização e segregação sócio-espacial na cidade de São José dos Campos-SP: o caso Pinheirinho. Geosul. Florianopolis. v. 25, n. 49, p. 123-158. 2010.

MARCUSE, P. Enclaves, sim; guetos, não: a segregação e o estado. In: Espaço e Debates. São Paulo: NERU. v. 24, n. 45, jan./jul. 2004, pp. 24-33.

MARICATO, E. As Ideias fora do lugar e o lugar fora das ideias. Planejamento urbano no Brasil. In: ARANTES, O. et. al. (Org.). A cidade do pensamento único. 
Desmanchando consensos. Petrópolis: Vozes, 2000. p. 121-192.

Conhecer para resolver a cidade ilegal. In Castriota, LB (org) Urbanização brasileira/redescobertas. Belo Horizonte, C/Arte, pp. 78-96. 2003.

O nó da terra. Ecodebates, 2008.

Disponível em:

http://www.ecodebate.com.br/2008/07/14/ono-da-terra-artigo-de-erminia-maricato.

Acesso em: ago. 2012.

Metrópole na periferia do capitalismo: ilegalidades, desigualdade e violência. São Paulo: Hucitec, 1996.

OLIVEIRA, F. O Estado e o Urbano no Brasil. Revista Estudos e Debates, n. 6, jun./set. 1982.

PEGORETTI, M. S.; SANCHES, S. P. A problemática da segregação espacial dos residentes da área rural: uma visão através da dimensão acesso e do sistema de transporte. II Encontro da ANPPAS, Indaiatuba, 2004. Disponível em: http://www.anppas.org.br/encontro_anual/en contro2/GT/GT11/michela.pdf. Acesso em: ago. 2012.

PMSJC - Primeiro Plano de Desfavelamento, Prefeitura Municipal de São José dos Campos, 1977.

PMSJC - Plano diretor de Desenvolvimento Integrado, Prefeitura Municipal de São José dos Campos, 1995.

PMSJC-NEPO - Atlas das condições de vida em São José dos Campos, Prefeitura Municipal de São José dos Campos em parceria com o NEPO - Núcleo de Estudos de População da UNICAMP, 2003.

PMSJC. Prefeitura Municipal de São José dos Campos. Dados Gerais. São José dos
Campos: Prefeitura Municipal de São José dos Campos, 2011. Disponível em: http://www.sjc.sp.gov.br/turista/dadosgerais. aspx. Acesso em: nov. 2011.

PMSJC. Prefeitura Municipal de São José dos Campos. Programas habitacionais. São José dos Campos: Prefeitura Municipal de São José dos Campos, 2012. Disponível em:

http://www.sjc.sp.gov.br/secretarias/habitaca

o/programas_habitacionais.aspx. Acesso em: jan. 2012.

ROSA FILHO, A. As Políticas públicas do poder executivo na remoção e/ou reurbanização de favelas em São José dos Campos - SP. São José dos Campos, Univap, 2002. Dissertação (mestrado em Planejamento Urbano e Regional). Programa de Pós-Graduação em Planejamento Urbano e Regional do Instituto de Pesquisa e Desenvolvimento, Universidade do Vale do Paraíba, São José dos Campos, 2002.

SILVA, D. D. Desigualdade social no Brasil: a questão habitacional em São José dos Campos-SP. São José dos Campos, Dissertação (mestrado em Planejamento Urbano e Regional). Programa de PósGraduação em Planejamento Urbano e Regional do Instituto de Pesquisa e Desenvolvimento, Universidade do Vale do Paraíba, São José dos Campos, 2008.

TORRES, H. G.; GONÇALVES, R. O mercado de terras em São Paulo e a continuada expansão da periferia. Revista Brasileira de Estudos Urbanos e Regionais, v. 9, n. 2, 2007.

VILLAÇA. F. Espaço Intra-Urbano no Brasil. São Paulo: Studio Nobel, 1998.

O que todo cidadão deve saber sobre habitação. São Paulo: Global, 1986. 